\title{
Prosthodontic Rehabilitation of a Completely Edentulous Cleft Palate Patient using an Unconventional Complete Denture-A Case Report
}

\section{Amanda Nadia Ferreira*, Prithika E, Meena Aras, Vidya Chitre and Ivy Coutinho}

Goa Dental College \& Hospital, India

\begin{abstract}
The management of adult completely edentulous patients with cleft palate, especially in whom, surgical intervention is not carried out pose a significant challenge to the prosthodontist. The overall goal of rehabilitating such individuals is focussed on improving acceptable speech, appearance, proper occlusion and masticatory function. This article describes the prosthetic rehabilitation of a cleft palate patient using an unconventional complete denture with a palatal obturator. Additionally, neutral zone impression technique for the resorbed mandibular arch and recording of palatogram was also done.
\end{abstract}

\section{Keywords: Cleft palate; Rehabilitation}

\section{Case Report}

A 48-year-old woman was referred to the Department of Prosthodontics, Goa Dental College and Hospital, for the rehabilitation of completely edentulous maxillary and mandibular arches and a cleft palate. On eliciting history, she referred to several previous attempts to wearing conventional dentures, which were not tolerated because of loss of retention and difficulty in speaking. Reconstructive cleft lip surgery was carried out when she was a child (patient does not remember exact age and no medical records available). However, no intervention was directed towards the cleft palate. Intraoral examination revealed completely edentulous upper arch with a palatal defect restricted to the premaxilla measuring approximately $3 \mathrm{~mm} \times 4 \mathrm{~mm} \times 5 \mathrm{~mm}$ and resorbed completely edentulous mandibular arch (Figure 1). Possible prosthetic treatment options were explained to the patient. However, due to financial reasons the patient declined an implant-retained prosthesis, and opted for a removable prosthesis with a palatal obturator for maxillary arch and a removable complete denture for the mandibular arch. It was decided to refine palatal contours with a palatogram for the upper prosthesis and a neutral zone impression technique for the lower prosthesis to improve retention and stability of the denture. Steps in complete denture fabrication were followed till recording of jaw relations and transfer to articulator. For recording the neutral zone, the lower wax occlusal rim was replaced with tissue conditioner material (Visco-Gel, Dentsply) supported with wire loops of 21 gauge (Samit, Dentokem) and three autopolymerising acrylic resin pillars; one anterior and two in the molar region as vertical stops. The patient was asked to carry out different functional movements like smiling, sucking, swallowing, licking the lips, whistling, pronouncing vowels and numbers, to mould the tissue conditioner material (Figure 2). An addition silicone putty (Aquasil, Soft putty, Regular set) index of the moulded rim was made and the artificial teeth were arranged in the

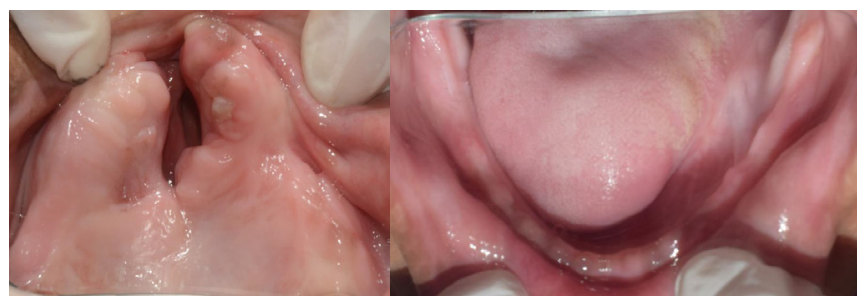

Figure 1: Maxillary arch with palatal defect and mandibular resorbed ridge. neutral zone following the index. Final try-in procedure was carried out. At the try-in stage, tissue conditioning material and green food color (Flying Bird, Artificial Food color, Green) was used to record a palatogram (Figure 3). It helps to record palatal contours during

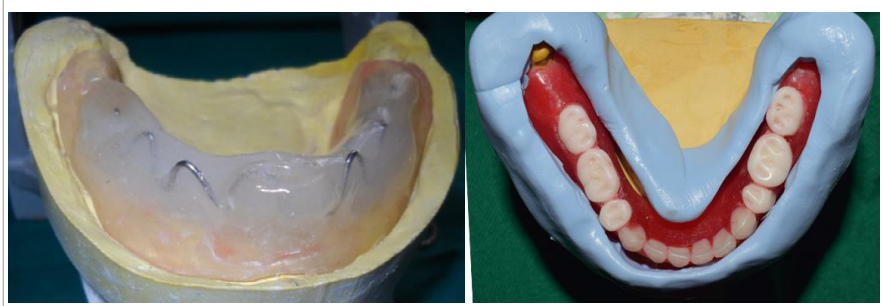

Figure 2: Neutral zone recorded with tissue conditioner and artificial teeth arranged in the neutral zone using a putty index.

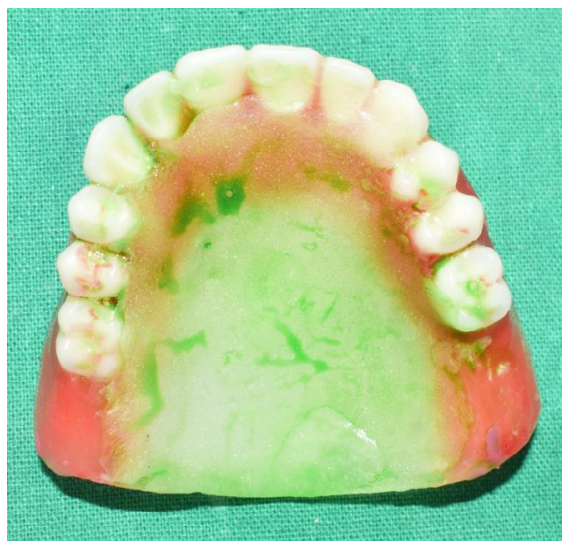

Figure 3: Palatogram recorded with tissue conditioner and green food color.

*Corresponding author: Amanda Nadia Ferreira, Goa Dental College \& Hospital, India, Tel: 0832245 9812; E-mail: Amanda12590@gmail.com

Received April 04, 2018; Accepted April 16, 2018; Published April 23, 2018

Citation: Ferreira AN, Prithika E, Aras M, Chitre V, Coutinho I (2018) Prosthodontic Rehabilitation of a Completely Edentulous Cleft Palate Patien using an Unconventional Complete Denture-A Case Report. Dentistry 8: 483. doi:10.4172/2161-1122.1000483

Copyright: (c) 2018 Ferreira AN, et al. This is an open-access article distributed under the terms of the Creative Commons Attribution License, which permits unrestricted use, distribution, and reproduction in any medium, provided the original author and source are credited. 
phonetics and make sure that the prosthesis does not interfere with speech of the patient. The waxed trial dentures were invested and dewaxed in conventional manner. A multiple U-loop shaped retainer made up of 20 gauge wire (Samit, Dentokem) was attached to the maxillary master cast after the dewaxing procedure. The purpose of the wire loop was to retain the obturator into the prosthesis. The dentures were acrylised using heat cure acrylic resin (DPI Heat Cure), finished

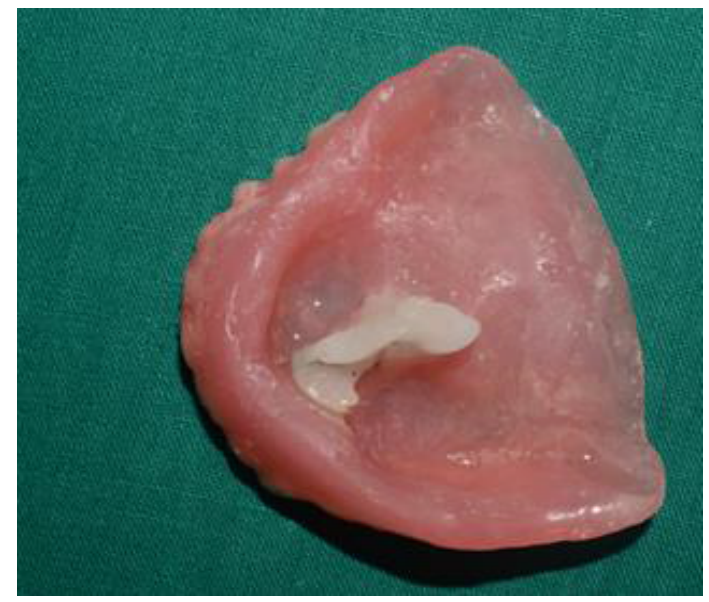

Figure 4: Palatal defect area relined with a soft denture liner

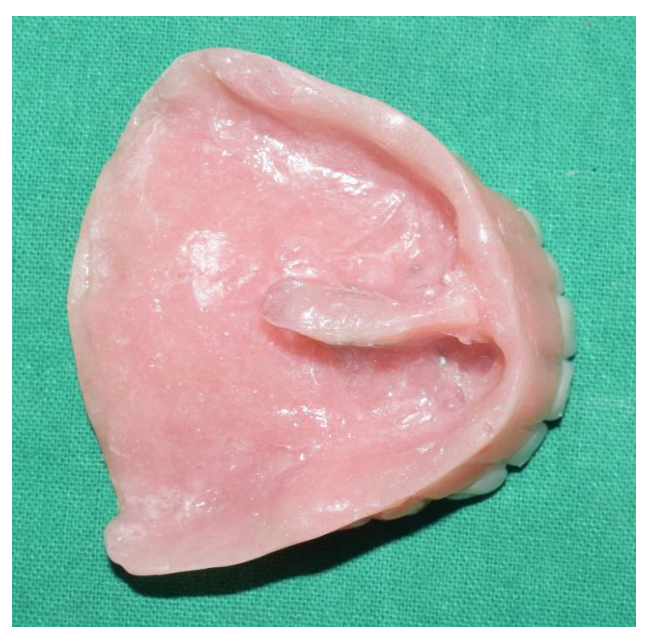

Figure 5: Palatal defect area relined with a hard denture liner after 1 month. and polished. The maxillary denture was relined in the cleft area with a temporary soft denture liner (GC Reline Soft, Tokyo) taking support from the retainer (Figure 4). Both dentures were delivered to the patient. The patient was educated in the care and maintenance of the prosthesis. Regular follow-up appointments were carried out. After an adaptation period of one month, the obturator was replaced by a permanent hard denture liner (GC Reline, Tokyo) (Figure 5). The finished prosthesis was seen to provide enough retention and stability to improve her chewing ability. There was also a remarkable improvement in speech and esthetics.

\section{Discussion}

The prevalence of cleft lip and palate in the general population depends on racial, ethnic and geographic factors, as well as on socioeconomic status. It has been estimated to range from 1:500 to 1:2500 live births [1]. Cleft lips occur in 20-30\% of cases, a cleft lip and palate in $35-50 \%$, and cleft palate alone in 30-45\% [2]. Treatment of cleft palates and cleft lips provide a tremendous challenge to the prosthodontist. For cleft palate patients, prosthetic restoration aids in developing normal speech, promotes deglutition and mastication, and separates the oral cavity from the nasal cavity [3]. It has been suggested that a prosthesis may improve both the physical and psychological performances of patients, as well as their quality of life [4]. An implant retained prosthetic appliance provides greater stability, retention and chewing efficiency than any other conventional prosthesis $[5,6]$. However in patients who refuse this invasive treatment approach, a conservative and conventional treatment is indicated. Generally, palatal obturators are used as simple solutions for the reconstruction of minor palatal defects. An obturator is indicated for a cleft palate patient when there is a need to improve the retention of conventional prosthesis. The use of a relined obturator is mainly indicated when the palatal defect is highly retentive, or when such a defect is very extensive or covered by an inadequately keratinized gingiva. By contrast, rigid obturators should only be used for small defects covered by keratinized gingiva [7].

In this case report, the patient was unhappy with her previous dentures as they were not retentive enough and also affected her phonetics. Use of palatal obturator with chairside relining provided optimum retention to the maxillary prosthesis. Palatogram showed marked improvement in the speech. Capturing the neutral zone and incorporating it in the denture led to adequate stability of the mandibular prosthesis (Figure 6).
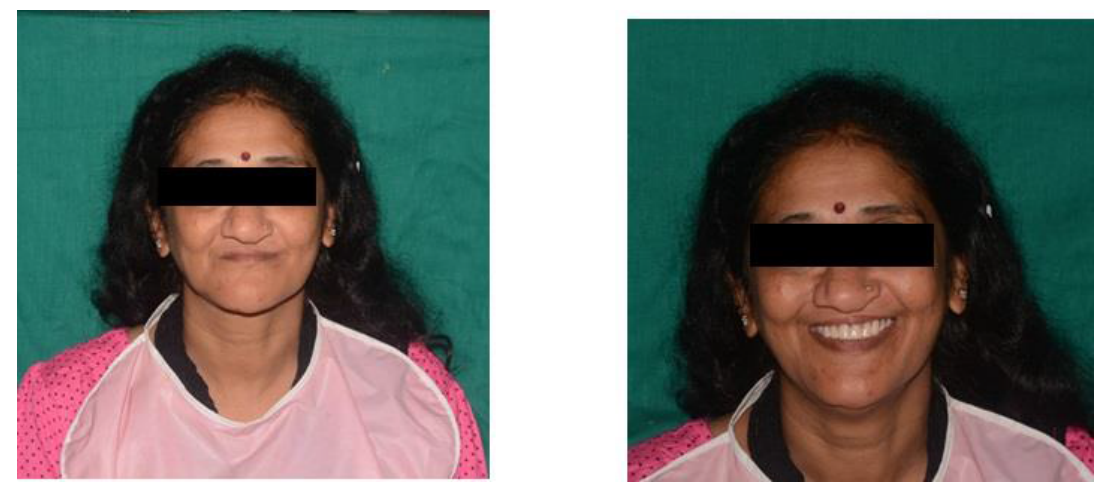

Figure 6: Pre op and post op extra oral photographs. 
Citation: Ferreira AN, Prithika E, Aras M, Chitre V, Coutinho I (2018) Prosthodontic Rehabilitation of a Completely Edentulous Cleft Palate Patient using an Unconventional Complete Denture-A Case Report. Dentistry 8: 483. doi:10.4172/2161-1122.1000483

\section{Conclusion}

The management of a completely edentulous cleft palate patient with palatal obturator and palatogram has been described. Prosthetic rehabilitation with an unconventional acrylic prosthesis is thus a conservative, economical, and quicker method and has lesser clinical complications than implant-retained prostheses.

\section{Declaration of Patient Consent}

The authors certify that they have obtained appropriate patient consent for use of images and other clinical information. Patient understands that due efforts have been made to conceal their identity but anonymity cannot be guaranteed.

\section{References}

1. Slayton RL, Williams L, Murray J, Wheeler JJ, Lidral AC, et al. (2003) Genetic
Association Studies of Cleft Lip and/or Palate with Hypodontia Outside the Cleft Region. Cleft Palate-Craniofac J 40: 274-279.

2. Abadi B, Johnson JD (1982) The prosthodontic management of cleft palate patients. J Prosthet Dent 48: 297-302.

3. Rahn AO, Boucher LJ (1970) Maxillofacial Prosthetics: Principles and Concepts, WB Saunders co, Philadelphia.

4. Hickey AJ, Salter M (2006) Prosthodontic and psychological factors in treating patients with congenital and craniofacial defects. J Prosthet Dent 95: 392-396.

5. Lund TW, Wade M (1993) Use of osseointegrated implants to support a maxillary denture for patient with repaired cleft lip and palate. Cleft Palate Craniofac J 30: 418-420.

6. Koyama S, Sasaki K, Inai T, Watanabe M (2005) Effects of defect configuration ,size and remaining teeth on masticatory function in postmaxillectomy patients. J Oral Rehabil 32: 635-641.

7. Montero J, Macedo C, Rodriguez M, López-Valverde A, Gómez de Diego R, et al. (2011) Prosthetic rehabilitation of an edentulous cleft palate using a denture with a palatal obturator: a clinical report. J Clin Exp Dent 3: 365-368. 